\title{
Gaseous Iron(II) and Iron(III) Complexes with BINOLate Ligands
}

\author{
Sophie Rochut, ${ }^{\text {a Jana Roithová, }}$, Detlef Schröder, ${ }^{\mathrm{c}}$ Francesca R. Novara, ${ }^{\mathrm{d}}$ \\ and Helmut Schwarz ${ }^{\mathrm{d}}$ \\ ${ }^{a}$ Université Pierre et Marie Curie, LADIR, Paris, France \\ ${ }^{b}$ Faculty of Science, Charles University in Prague, Prague, Czech Republic \\ ${ }^{\mathrm{c}}$ Institute of Organic Chemistry and Biochemistry, Prague, Czech Republic \\ ${ }^{\mathrm{d}}$ Institut für Chemie der Technischen Universität Berlin, Berlin, Germany
}

Electrospray ionization (ESI) of dilute solutions of 1,1'-bi-2-naphthol (BINOL) and iron(II) or iron(III) sulfate in methanol/water allows the generation of monocationic complexes of iron and deprotonated BINOL ligands with additional methanol molecules in the coordination sphere, and the types of complexes formed can be controlled by the valence of the iron precursors used in ESI. Thus, iron(II) sulfate leads to $\left[(\mathrm{BINOLate}) \mathrm{Fe}\left(\mathrm{CH}_{3} \mathrm{OH}\right)_{n}\right]^{+}$complexes $(n$ $=0-3)$, whereas usage of iron(III) sulfate allows the generation of [(BINOLdiate)$\left.\mathrm{Fe}\left(\mathrm{CH}_{3} \mathrm{OH}\right)_{n}\right]^{+}$cations $(n=0-2)$; here, BINOLate and BINOLdiate stand for singly and doubly deprotonated BINOL, respectively. Upon collision-induced dissociation, the mass-selected ions with $n>0$ first lose the methanol ligands and then undergo characteristic fragmentations. Bare [(BINOLdiate)Fe] ${ }^{+}$, a formal iron(III) species, undergoes decarbonylation, which is known as a typical fragmentation of ionized phenols and phenolates either as free species or as the corresponding metal complexes. The bare [(BINOLate)Fe ${ }^{+}$cation, on the other hand, preferentially loses neutral $\mathrm{FeOH}$ to afford an organic $\mathrm{C}_{20} \mathrm{H}_{12} \mathrm{O}^{+} \cdot$ cation radical, which most likely corresponds to ionized 1,1'-dinaphthofurane. (J Am Soc Mass Spectrom 2008, 19, 121-125) @ 2008 American Society for Mass Spectrometry

$\mathrm{B}$ INOL (1,1'-bi-2-naphthol) is among the most important chiral ligands used in metal-mediated asymmetric synthesis [1]. Despite a huge base of knowledge, however, gas-phase models that would permit a detailed understanding of enantioselective reactions at a molecular level are still relatively scarce [2-4]. In the course of ongoing studies of possible systems that allow probing of chiral reactions with mass spectrometric means $[3,5,6]$, we here report on the generation of BINOL complexes of iron(II) and iron(III) by electrospray ionization (ESI) and on the fragmentation behavior of the ions formed to provide a foundation for future studies about possible enantioselective effects in the ion/molecule reactions of these gaseous complexes.

\section{Experimental}

The experiments were performed using a VG BIO-Q mass spectrometer, which consists of an ESI source combined with a tandem mass spectrometer of QHQ configuration ( $\mathrm{Q}$ stands for quadrupole and $\mathrm{H}$ for hexapole) as described in detail elsewhere [7]. In the present experiments, millimolar solutions of BINOL

Address reprint requests to Dr. Detlef Schröder, Czech Academy of Sciences, Institute for Organic Chemistry and Biochemistry, 16610 Praguw 6, Czech Republic. E-mail: detlef.schroeder@uochb.cas.cz

J. Roithová is also affiliated with the Institute of Organic Chemistry and Biochemistry, Prague, Czech Republic. and iron(II) or iron(III) sulfate, respectively, in methanol/water (1:1) were introduced through a fused-silica capillary to the ESI source by a syringe pump $(\sim 5$ $\mu \mathrm{L} / \mathrm{min}$ ). Nitrogen was used as nebulizing and drying gas at a source temperature of about $100^{\circ} \mathrm{C}$. Maximal yields of the desired ions (see following text) were achieved by adjusting the cone voltage to between 30 and $90 \mathrm{~V}$, respectively. For collision-induced dissociation (CID) at low collision energies, the ions of interest were mass-selected using Q1, interacted with xenon as a collision gas in the hexapole $\mathrm{H}$ at variable collision energies $\left(E_{\mathrm{lab}}=0-20 \mathrm{eV}\right)$, while scanning Q2 to monitor the ionic products. In most cases, this pressure of xenon (typically $2 \times 10^{-4}$ mbar) corresponds to single-collision conditions, but for some of the more weakly bound methanol complexes, the CID cross sections are very large, such that a considerable number of multiple collisions take place [8]. Given that the primary aim of the CID experiments reported here is the illustration of trends in relative binding energies, this aspect is not pursued any further. The same holds true for the internal energy content of the ions, which somewhat depends on size of the complexes as well as the cone voltage used, but poses no particular obstacles for the purpose of this work.

As pointed out previously, the VG Bio-Q does not allow one to directly extract quantitative threshold information from CID experiments due to several limitations of the commercial instrument [7]. For weakly 
bound ions [8, 9], for example, even at $E_{\text {lab }}=0 \mathrm{eV}$ a non-negligible amount of ion decay is observed, which is in part attributed to the presence of collision gas not only in the hexapole, but also in the focusing regions between the mass analyzers. Note that this dissociation does not correspond to metastable ions because it does not occur in the absence of collision gas. To a first approximation, however, the energy dependence of the product distributions in the CID spectra can be approximated by a sigmoid function [10], which allows one to extract some semi-quantitative information about the energetics of the ions examined [11]. Thus, the energy dependence of the CID fragments can be approximated by sigmoid functions of the type $I_{i}\left(E_{\mathrm{CM}}\right)=[\mathrm{BR} /(1+$ $e^{\left.\left(E_{12}-E_{\mathrm{CM}}\right)^{b}\right]}$ using a least-square criterion; for the parent ion $\mathrm{M}$, the relation is: $I_{M}\left(E_{\mathrm{CM}}\right)=\{1-\Sigma[\mathrm{BR} /(1+$ $\left.\left.e^{\left.\left(E_{12, i}-E_{\mathrm{cm}}\right) b_{i}\right)}\right]\right\}$. Here, $B R_{\mathrm{i}}$ stands for the branching ratio of a particular product ion $\left(\Sigma B R_{\mathrm{i}}=1\right) ; E_{1 / 2}$ is the energy at which the sigmoid function of ion intensities has reached half of its maximum; $E_{\mathrm{CM}}$ is the collision energy in the center-of-mass frame $\left[E_{\mathrm{CM}}=m_{\mathrm{T}} /\left(m_{\mathrm{T}}+m_{\mathrm{I}}\right) \times\right.$ $E_{\mathrm{lab}}$, where $m_{\mathrm{T}}$ and $m_{\mathrm{I}}$ stand for the masses of the collision gas and the ion, respectively]; and $b$ describes the rise of the sigmoid curve. In consecutive dissociations, all secondary product ions are added to the intensity of the primary fragment. Further, non-negligible ion decay at $E_{\text {lab }}=0 \mathrm{eV}$ as well as some fraction of non-fragmenting parent ions at large collision energies are acknowledged by means of appropriate scaling and normalization procedures. This empirical, yet physically reasonable approach is able to reproduce the measured ion yields quite well; note, however, that this simplified formalism does not explicitly include a treatment of competitive branching ratios at elevated energies. It is also quite obvious that the term $E_{1 / 2}$ used in the exponent does not correspond to the intrinsic appearance energies of the fragmentation of interest, not to speak of the corresponding thermochemical thresholds at $0 \mathrm{~K}$. The phenomenological appearance energies given earlier are derived from linear extrapolations of the rise of the sigmoid curves at $E_{1 / 2}$ to the baseline.

\section{Results and Discussion}

Before addressing the ions formed in the presence of BINOL, let us briefly consider the leading ions formed upon ESI of dilute solution of iron(II) and iron(III) sulfate, respectively, in methanol/water (1:1). In the ESI process, the ionic species present in solution are gently transferred into the gas phase and it can thus be expected that the oxidation state of the metal salt used is also maintained in the ionic species being observed in the mass spectrometer.

Under mild conditions of ionization, ESI of iron(II) sulfate in methanol/water leads to a series of complexes of the type $\left[\left(\mathrm{CH}_{3} \mathrm{O}\right) \mathrm{Fe}\left(\mathrm{CH}_{3} \mathrm{OH}\right)_{n}\right]^{+}(\mathrm{m} / z=87+32 n$ for the ${ }^{56} \mathrm{Fe}$ isotope) with up to $n=5$ at the softest conditions (i.e., low source temperature, low cone voltage) $[12,13]$, along with dications of the type
$\left[\mathrm{Fe}\left(\mathrm{CH}_{3} \mathrm{OH}\right)_{n}\right]^{2+}\left(m / z=28+16 n\right.$ for the ${ }^{56} \mathrm{Fe}$ isotope $)$ with $n=3-8$. The complete absence of the sulfate counterion in the leading ions can be attributed to the poor coordination properties of $\mathrm{SO}_{4}^{2-}$ as a ligand, such that almost complete heterolysis of $\mathrm{FeSO}_{4}$ into $\mathrm{Fe}_{\text {solv }}^{2+}$ and $\mathrm{SO}_{4 \text { solv }}^{2-}$ can be assumed. Upon transfer into the gas phase, the dicationic iron center is either desorbed as an intact solvated dication or binds a methoxo ligand concomitant with proton transfer to the solution. Further note that the water required as a co-solvent for the dissolution of the iron sulfates does not appear in any of the leading ions, even though it is present with the highest molar fraction in the solution.

In marked contrast, ESI of iron(III) sulfate in methanol/water does not lead to a corresponding series of $\left[\left(\mathrm{CH}_{3} \mathrm{O}\right)_{2} \mathrm{Fe}\left(\mathrm{CH}_{3} \mathrm{OH}\right)_{n}\right]^{+}$species $(\mathrm{m} / \mathrm{z}=118+32 n$ for the ${ }^{56} \mathrm{Fe}$ isotope), most likely because the solvent cannot sufficiently support heterolysis to the solvated trication $\mathrm{Fe}_{\text {solv }}^{3+}[14,15]$. Instead, anion rebound to a contact-ion pair (CIP) [16] takes place, either already in solution [17] or upon desolvation of the droplets upon ESI, leading to a series of $\left[\mathrm{FeSO}_{4}\left(\mathrm{CH}_{3} \mathrm{OH}\right)_{n}\right]^{+}$monocations $(\mathrm{m} / \mathrm{z}=152$ $+32 n$ for the ${ }^{56} \mathrm{Fe}$ isotope) with $n=2-5$.

Upon addition of traces of BINOL to the abovementioned solutions of iron(II) sulfate, the corresponding complexes [(BINOLate) $\left.\mathrm{Fe}\left(\mathrm{CH}_{3} \mathrm{OH}\right)_{n}\right]^{+}(\mathrm{m} / \mathrm{z}=341+$ $32 n$ for the ${ }^{56} \mathrm{Fe}$ isotope) with $n=0-3$ are formed in good yields upon ESI; note that throughout this report BINOLate and BINOLdiate stand for singly and doubly deprotonated BINOL, respectively. Generation of this series of ions can be accounted for by a replacement of the methoxo ligand in $\left[\left(\mathrm{CH}_{3} \mathrm{O}\right) \mathrm{Fe}\left(\mathrm{CH}_{3} \mathrm{OH}\right)_{n}\right]^{+}$by (deprotonated) BINOL, which is more acidic than methanol and, moreover, a chelating ligand. Likewise, although in somewhat lower yields, ESI of diluted of iron(III) sulfate in the presence of BINOL leads to ions that correspond to [(BINOLdiate) $\left.\mathrm{Fe}\left(\mathrm{CH}_{3} \mathrm{OH}\right)_{n}\right]^{+}(\mathrm{m} / \mathrm{z}=$ $340+32 n$ for the ${ }^{56} \mathrm{Fe}$ isotope) with $n=0-2$. The lower yields with iron(III) sulfate as a precursor can be attributed to a more difficult replacement of the sulfate counterion in the $\mathrm{FeSO}_{4}^{+}$unit by the BINOLdiate dianion because this requires the liberation of sulfuric acid. Consistent with this view, the ESI mass spectra show large signals for protonated BINOL $(\mathrm{m} / \mathrm{z}=287)$; also, the cation radical $\mathrm{BINOL}^{+}(\mathrm{m} / \mathrm{z}=286)$ is observed in considerable amounts.

By comparing these results, we conclude that the type of the BINOL complexes formed can be controlled by the valence state of the metal precursor used, in that [(BINOLate) $\left.\mathrm{Fe}\left(\mathrm{CH}_{3} \mathrm{OH}\right)_{n}\right]^{+}$corresponds to a formal iron(II) compound and [(BINOLdiate) $\left.\mathrm{Fe}\left(\mathrm{CH}_{3} \mathrm{OH}\right)_{n}\right]^{+}$ formally contains iron(III). In a more general perspective, the generation of these metal complexes of (deprotonated) BINOL with additional alkanol ligands may enable the investigation of enantioselective reactions in the gas phase, if (chiral) 2-alkanols instead of methanol are used [5]. Here, however, we focus on the fragmentation reactions of the BINOL complexes to provide 
(a) $\left[(\mathrm{BINOLate}) \mathrm{Fe}\left(\mathrm{CH}_{3} \mathrm{OH}\right)\right]^{+}$

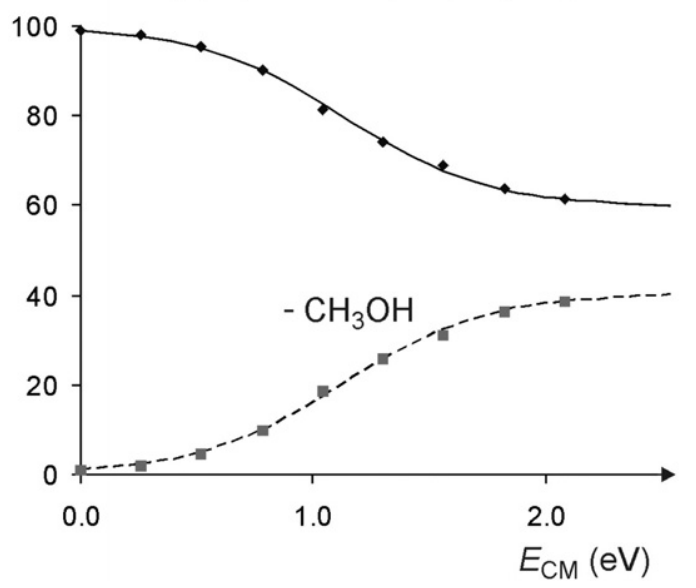

(b) $\left[(\mathrm{BINOLate}) \mathrm{Fe}\left(\mathrm{CH}_{3} \mathrm{OH}\right)_{2}\right]^{+}$

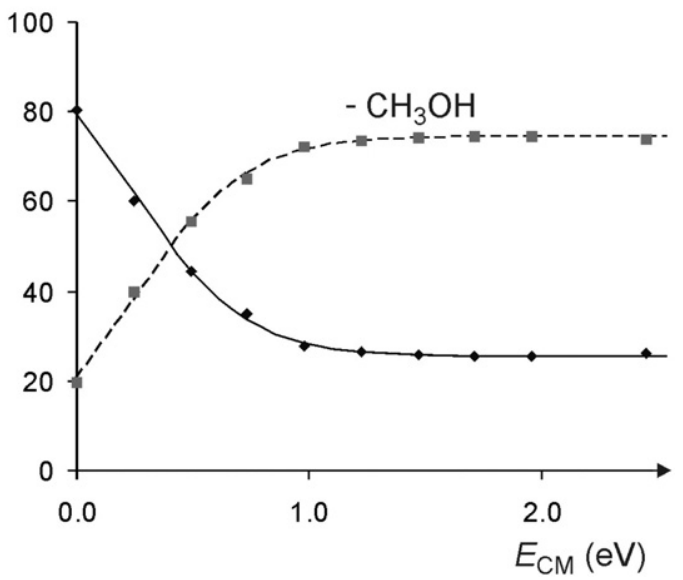

Figure 1. Breakdown graphs for the CID of mass-selected (a) [(BINOLate) $\left.\mathrm{Fe}\left(\mathrm{CH}_{3} \mathrm{OH}\right)\right]^{+}(\mathrm{m} / \mathrm{z}=373)$ and (b) $\left[(\mathrm{BINOLate}) \mathrm{Fe}\left(\mathrm{CH}_{3} \mathrm{OH}\right)_{2}\right]^{+}(\mathrm{m} / \mathrm{z}=405)$, showing the abundances of the parent ions $(\bullet)$ and the methanol-loss fragments $(\boldsymbol{\square})$ as a function of the collision energy (given in $\mathrm{eV}$ in the center of mass frame).

some basic knowledge about the characteristic properties of metal/BINOL complexes in the gas phase.

Upon CID of mass-selected [(BINOLate) $\left.\mathrm{Fe}\left(\mathrm{CH}_{3} \mathrm{OH}\right)\right]^{+}$, loss of methanol is observed as the exclusive dissociation channel at low collision energy (Figure 1a). Likewise, only sequential losses of the coordinated solvent occur from [(BINOLate) $\left.\mathrm{Fe}\left(\mathrm{CH}_{3} \mathrm{OH}\right)_{2}\right]^{+}$. In the case of the latter, dissociation is already observed at a collision energy nominally set to $0 \mathrm{eV}$ (Figure 1b), which reflects a relatively weak bond of the second methanol molecule, such that the kinetic energy spread of the incident beam $(\sim 0.4 \mathrm{eV})$ as well as the internal energy content of the ions generated upon ESI already can bring about collision-induced fragmentation $[8,9]$.

Phenomenological analysis of the breakdown diagram in Figure 1a leads to an appearance energy of $A E_{373 \rightarrow 341}=0.5$ $\mathrm{eV}$ for the loss of methanol from [(BINOLate) $\left.\mathrm{Fe}\left(\mathrm{CH}_{3} \mathrm{OH}\right)\right]^{+}$, whereas a formally negative $A E_{405 \rightarrow 373}=-0.2 \mathrm{eV}$ is obtained for the more weakly bound methanol ligand in [(BINOLate) $\left.\mathrm{Fe}\left(\mathrm{CH}_{3} \mathrm{OH}\right)_{2}\right]^{+}[8,11]$. From a structural perspective, the absence of other fragmentations than mere methanol loss is fully consistent with the suggested structure $\left[(\mathrm{BINOLate}) \mathrm{Fe}\left(\mathrm{CH}_{3} \mathrm{OH}\right)_{n}\right]^{+}$. If the tautomeric $\left[\left(\mathrm{CH}_{3} \mathrm{O}\right) \mathrm{Fe}(\mathrm{BINOL})\left(\mathrm{CH}_{3} \mathrm{OH}\right)_{n-1}\right]^{+}$complexes, bearing a methoxo ligand, were present, ample evidence about the gas-phase chemistry of transition-metal alkoxides implies that loss of formaldehyde should be able to compete at least at elevated collision energies [12, 13, 18-20]. Deprotonation of BINOL rather than methanol in the complex is also suggested by comparison of the gas-phase acidity of methanol $\left(1569 \mathrm{~kJ} \mathrm{~mol}^{-1}\right)$ versus that of phenols (e.g., 1408 $\mathrm{kJ} \mathrm{mol}^{-1}$ for 2-naphthol) [21].

Upon CID of bare (BINOLate)Fe ${ }^{+}$, loss of carbon monoxide and dehydration, respectively, are observed first at low collision energies. These two types of fragmentations are typical for iron complexes of phenol and related hydroxyarenes [22-26]; the corresponding fragmentations of phenol $/ \mathrm{Fe}^{+}$, for example, lead to benzyne $/ \mathrm{Fe}^{+}$(loss of water) and cyclopentadiene $/ \mathrm{Fe}^{+}$ (loss of $\mathrm{CO}$ ) [22, 27]. At elevated collision energies, however, the expulsion of neutral $\mathrm{FeOH}$ dominates the fragmentation behavior (Figure 2).

With respect to these competing channels, it is instructive to consider the energy behavior in some more detail. Thus, the losses of water and carbon monoxide both have phenomenological appearance energies of about $0.8 \mathrm{eV}$ and then rise very smoothly, whereas the loss of neutral $\mathrm{FeOH}$ shows a steeper rise with $A E_{341 \rightarrow 268}=2.8 \mathrm{eV}$. Such a behavior indicates that the formation of $\mathrm{CO}$ as well as the elimination of $\mathrm{H}_{2} \mathrm{O}$ involve structural rearrangements associated with entropically demanding pathways leading to energetically favorable products, whereas the expulsion of $\mathrm{FeOH}$ can occur in a direct manner as a continuously endothermic process not being subject to entropic restrictions [12,

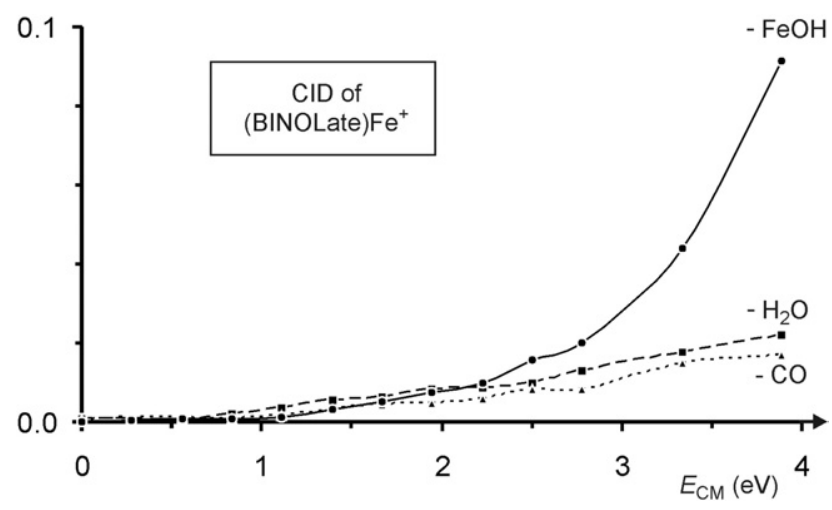

Figure 2. Fractional abundances $\left(\Sigma_{\text {ions }}=1\right.$; including the parent ion, which exceeds the vertical scale of Figure 2 at all collision energies investigated) of the fragments formed upon CID of mass-selected (BINOLate) $\mathrm{Fe}^{+}(\mathrm{m} / \mathrm{z}=341)$ as a function of the collision energy (given in $\mathrm{eV}$ in the center of mass frame). 
13]. As a plausible rationale for this behavior, we propose the scenario depicted in Scheme $\mathbf{1}$ in that high collision energies lead to an extrusion of neutral $\mathrm{FeOH}$ from the BINOLate complex $\mathbf{1}$ concomitant with formation of the molecular ion of the dinaphthofurane 2 [28].

Further support for the formation of the molecular ion $2^{+}$comes from CID of the mass-selected $\mathrm{C}_{20} \mathrm{H}_{12} \mathrm{O}^{+}$cation $(\mathrm{m} / \mathrm{z}=268)$ generated in the ESI source under more drastic conditions of ionization. Thus, the leading fragmentation of so-formed $\mathrm{C}_{20} \mathrm{H}_{12} \mathrm{O}^{+} \cdot$ corresponds to a loss of neutral $\mathrm{CHO}$, which parallels the predominant dissociation pathways in the mass spectra of benzo- and naphthofuranes [21] and is a generally frequent decomposition pathway of ionized oxyarenes $[29,30]$. Location of the positive charge on the organic fragment, rather than the metal, is also supported by consideration of the respective ionization energies, that is $I E(\mathrm{FeOH})=7.67 \pm 0.06 \mathrm{eV}$ [31] compared to a value of $\operatorname{IE}(2)=6.93 \mathrm{eV}$ predicted by B3LYP / 6-311G* calculations performed using Gaussian 03 [32]. We note in passing that the stabilization of the ionized furane by the naphtho-annellation is quite remarkable, given that the $I E$ of plane furane is $8.88 \mathrm{eV}$ [21] and that of dibenzofurane is $7.90 \mathrm{eV}$ [33] $(7.81 \mathrm{eV}$ is predicted with B3LYP/6-311G*).

The behavior of the corresponding iron(III) species, $\left[(\mathrm{BINOLdiate}) \mathrm{Fe}\left(\mathrm{CH}_{3} \mathrm{OH}\right)_{n}\right]^{+}$, is quite similar to the solvated iron(II) species in that sequential losses of methanol are observed exclusively. With $A E_{372 \rightarrow 340}=$ $1.0 \mathrm{eV}$, the binding energy of the methanol in $\left[(\mathrm{BINOLdiate}) \mathrm{Fe}\left(\mathrm{CH}_{3} \mathrm{OH}\right)\right]^{+}$is somewhat larger than that found for $\left[(\mathrm{BINOLate}) \mathrm{Fe}\left(\mathrm{CH}_{3} \mathrm{OH}\right)\right]^{+}$, which is consistent with a tighter binding for the higher valent iron(III) species. For the second methanol ligand, the experimentally determined phenomenological $A E_{404 \rightarrow 372}$ is slightly negative $(-0.1 \mathrm{eV})$ for the reasons discussed earlier. As a minute side reaction, the formation of $(\mathrm{BINOL}) \mathrm{Fe}^{+}(\mathrm{m} / \mathrm{z}=342)$ is observed upon CID of both methanol complexes, which implies an oxidation of methanol to formaldehyde concomitant with the reduction of iron(III) in [(BINOLdiate) $\left.\mathrm{Fe}\left(\mathrm{CH}_{3} \mathrm{OH}\right)_{n}\right]^{+}$to formal iron(I) in $[(\mathrm{BINOL}) \mathrm{Fe}]^{+}$. A redox process from iron(III) to iron(I) may actually also play a role in the bare (BINOLdiate)Fe ${ }^{+}$cation itself because phenolates are redox-active ligands [34] and thus a valence tautomerization may connect structure 3 with the quinoide iron(I) complex 3a (Scheme 2) [23, 35].
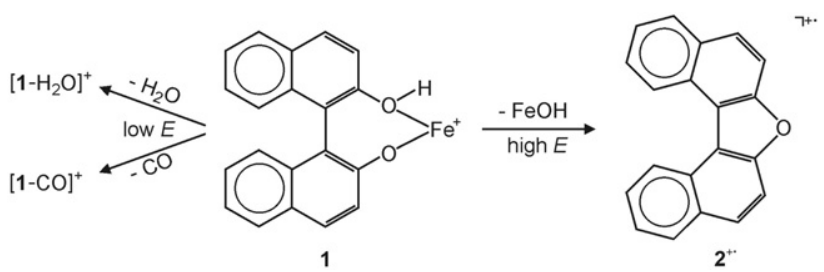

Scheme 1. Suggested formation of ionized dinaphthofurane upon extrusion of neutral $\mathrm{FeOH}$ from (BINOLate) $\mathrm{Fe}^{+}$at elevated collision energy.

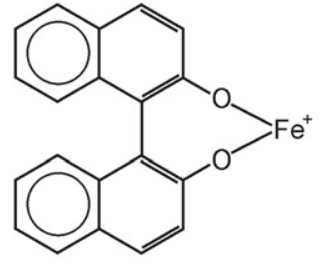

3

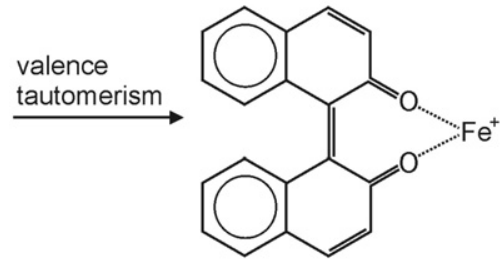

$3 a$
Scheme 2. Valence tautomerism of the formal iron(III) compound (BINOLdiate) $\mathrm{Fe}^{+}, 3$, and the quinoide form $3 \mathbf{a}$ with formal iron(I).

Indirect support for this suggestion is further provided by the experimental observation that the massselected ion with $\mathrm{m} / \mathrm{z}=340$, formally corresponding to (BINOLdiate)Fe ${ }^{+}$, undergoes decarbonylation as the only significant fragmentation upon CID, which can be understood by a contraction of one of the bi-cycles in structure 3a to an indene skeleton [22-27]. Loss of neutral FeO to presumably afford ionized dinaphthofurane $\mathbf{2}^{+}$in analogy to Scheme $\mathbf{1}$ is not observed at all, which is consistent with a low oxidation state of iron in the complex, i.e., the valence tautomer 3a rather than 3.

\section{Conclusions}

Electrospray mass spectrometry can be used for the selective generation of gaseous transition-metal complexes bearing ligands derived from BINOL. The valence state of the complexes initially formed under soft ESI conditions can selectively be controlled by the choice of the metal salt. The ion yields achieved are sufficient for further reactivity studies and the fragmentation patterns imply a clean coordination of methanol ligands to the chiral metal center, thus offering further perspectives to probe possible enantioselective reactions of gaseous ions in the future by replacing the solvent molecules with chiral substrates. Finally, we note in passing that the approach is not limited to iron and, in analogous manner, we have successfully generated similar BINOLate complexes of V(III), V(IV), $\mathrm{Mn}(\mathrm{II}), \mathrm{Co}(\mathrm{II}), \mathrm{Ni}(\mathrm{II})$, and $\mathrm{Cu}(\mathrm{II})$, respectively.

\section{Acknowledgments}

This work was supported by the Deutsche Forschungsgemeinschaft, the Fonds der Chemischen Industrie, the Grant Agency of the Czech Academy of Sciences (KJB400550704) and the Ministry of Education for the Czech Republic (MSM0021620857).

\section{References}

1. For a recent example, see: van den Berg, M.; Minnaard, A. J.; Haak, R. M.; Leeman, M.; Schudde, E. P.; Meetsma, A.; Feringa, B. L.; de Vries, A. H. M.; Maljaars, C. E. P.; Willans, C. E.; Hyett, D.; Boogers, J. A. F.; Henderickx, H. J. W.; de Vries, J. G. Monodentate Phosphoramidites: A Breakthrough in Rhodium-Catalysed Asymmetric Hydrogenation of Olefins. Adv. Synth. Catal. 2003, 345, 308-323.

2. Splitter, J. S.; Tureček, F. Applications of Mass Spectrometry to Organic Stereochemistry. VCH-Publishers: Weinheim, Germany, 1994.

3. Schröder, D.; Schwarz, H. Diastereoselective Effects in Gas-Phase Ion Chemistry. Top. Curr. Chem. 2003, 225, 133-152. 
4. Speranza, M. Enantioselectivity in Gas-Phase Ion-Molecule Reactions. Int. J. Mass Spectrom. 2004, 232, 277-317.

5. Schröder, D.; Schwarz, H. Diastereo- and Enantioselective Bond Activation of Alkanols by Gaseous Metal Ions. Int. J. Mass Spectrom. 2004, $231,139-146$.

6. Roithová, J.; Schröder, D. Gas-Phase Study of the C-C Coupling of Naphthol Catalyzed by $\mathrm{Cu}^{\mathrm{II}}$. TMEDA: Evidence for the Key Role of Binuclear Clusters. Chem. Eur. J., in press.

7. Schröder, D.; Weiske, T.; Schwarz, H. Dissociation Behavior of $\mathrm{Cu}(\mathrm{u}-$ rea $)^{+}$Complexes Generated by Electrospray Ionization. Int. J. Mass Spectrom. 2002, 219, 729-738.

8. Jagoda-Cwiklik, B.; Jungwirth, P.; Rulišek, L.; Milko, P.; Roithová, J. Lemaire, J.; Maitre, P.; Ortega, J. M.; Schröder, D. Micro-hydration of the $\mathrm{MgNO}_{3}{ }^{+}$Cation in the Gas Phase. Chem. Phys. Chem. 2007, 8, 1629-1639.

9. Schröder, D.; Semialjac, M.; Schwarz, H. Secondary Kinetic Isotope Effects in Cation-bound Dimers of Acetone $\left(\mathrm{C}_{3} \mathrm{H}_{6} \mathrm{O}\right) \mathrm{M}\left(\mathrm{C}_{3} \mathrm{D}_{6} \mathrm{O}\right)^{+}$with $\mathrm{M}$ $=\mathrm{H}, \mathrm{Li}, \mathrm{Na}, \mathrm{K}, \mathrm{Rb}, \mathrm{Ag}$, and Cs. Int. I. Mass Spectrom. 2004, 233, 103-109.

10. Bouchoux, G.; Leblanc, D.; Salpin, J. Y. A Relationship between the Kinetics and Thermochemistry of Proton Transfer Reactions in the Gas Phase. Int. J. Mass Spectrom. 1996, 153, 37-48.

11. Schröder, D.; Engeser, M.; Brönstrup, M.; Daniel, C.; Spandl, J.; Hartl, H. Ion Chemistry of the Hexanuclear Methoxo-Oxovanadium Cluster $\mathrm{V}_{6} \mathrm{O}_{7}\left(\mathrm{OCH}_{3}\right)_{12}$. Int. J. Mass Spectrom. 2003, 228, 743-757.

12. Trage, C.; Diefenbach, M.; Schröder, D.; Schwarz, H. Innocent and Less-innocent Solvent Ligands: A Systematic Investigation of Cationic Iron Chloride/Alcohol Complexes by Electrospray Ionization Mass Spectrometry Complemented by DFT Calculations. Chem. Eur. J. 2006, $12,2454-2464$

13. Grüne, P.; Trage, C.; Schröder, D.; Schwarz, H., Solvent and Ligand Effects on the Structures of Iron Halide Cations in the Gas Phase. Eur. J. Inorg. Chem. 2006, 22, 4546-4552.

14. Shvartsburg, A. A. Acetonitrile Complexes of Triply Charged Metal Ions: Are Ligated Trications Intrinsically More Prone to Charge Reduction than Dications? Chem. Phys. Lett. 2002, 360, 479-486.

15. Shvartsburg, A. A. DMSO Complexes of Trivalent Metal Ions: First Microsolvated Trications Outside of Group 3. J. Am. Chem. Soc. 2002, 124, 12343-12351.

16. Marcus, Y.; Hefter, G. Ion Pairing. Chem. Rev. 2006, 106, 4585-4621.

17. Magini, M. Solute Structuring in Aqueous Iron(III) Sulfate-SolutionsEvidence for the Formation of Iron(III)-Sulfate Complexes. J. Chem. Phys. 1979, 70, 317-324

18. Cassady, C. J.; Freiser, B. S. Gas-Phase Reactions of Transition-Metal Ions with Methyl Nitrite and Nitromethane. J. Am. Chem. Soc. 1985, 107, $1566-1573$.

19. Schröder, D.; Schwarz, H. Iron(II)-mediated Hydride and Methanide Transfer to Carbonyl Groups. Angew. Chem. Int. Ed. Engl. 1990, 29, 910-912.
20. Fiedler, A.; Schröder, D.; Schwarz, H.; Tjelta, B. L.; Armentrout, P. B. "Bare" Iron Methoxide Cation: A Simple Model to Probe the Mechanism of Beta-hydrogen Transfer in Organometallic Compounds. J. Am. Chem. Soc. 1996, 118, 5047-5055.

21. Taken from the NIST Standard Reference Database Number 69, June 2005 Release, National Institute of Standards, Gaithersburg, MD; see http:// webbook.nist.gov/chemistry/

22. Schröder, D.; Schwarz, H. Benzene Oxidation by Bare $\mathrm{FeO}^{+}$in the Gas-Phase. Helv. Chim. Acta 1992, 75, 1281-1287.

23. Schröder, D.; Zummack, W.; Schwarz, H. Functional-Group Interaction in the $\mathrm{Fe}^{+}$-mediated Degradation of Phenols and Their Methyl Ethers. Organometallics 1993, 12, 1079-1085.

24. Becker, H.; Schröder, D.; Zummack, W.; Schwarz, H. Generation, Fragmentation, and Interconversion Processes of $\left[\mathrm{Fe}, \mathrm{C}_{6}, \mathrm{H}_{6}, \mathrm{O}\right]^{+}$Isomers Relevant for the Oxygenation of Aromatic Hydrocarbons. J. Am. Chem. Soc. 1994, 116, 1096-1100.

25. Brönstrup, M.: Trage, C.: Schröder, D.; Schwarz, H. Regioselective Activation of Ipso and Ortho Positions in Chlorobenzene by $\mathrm{FeO}^{+}$. J. Am. Chem. Soc. 2000, 122, 699-704.

26. Brönstrup, M.; Schröder, D.; Schwarz, H. A Mechanistic Study of the $\mathrm{FeO}^{+}$-mediated Decomposition Pathways of Phenol, Anisol, and Their Thio Analogues. Chem. Eur. J. 2000, 6, 91-104.

27. Xu, Y. C.; Lee, S. A.; Freiser, B. S.; Bauschlicher, C. W., Jr. Organometallic Distonic Ions: $\left(p-\mathrm{C}_{6} \mathrm{H}_{4}{ }^{\bullet}\right) \mathrm{Fe}^{+}$. J. Am. Chem. Soc. 1995, 117, 54135414 , and references therein

28. Wang, B.; Li, M.; Xu, S.; Song, H.; Wang, B. Q. A General Synthetic Route to Dibenzospiropyrans and Dinaphthospiropyrans from Dibenzofuran and Dinaphthofuran. Synthesis (Stuttgart) 2007, 11, 1643-1648.

29. Roithová, J.; Schröder, D.; Schwarz, H. Substituent Effects in the Unimolecular Fragmentation of Anisole Dication Derivatives. J. Phys. Chem. A 2004, 108, 5060-5068.

30. Roithová, J.; Schröder, D.; Schwarz, H. Decomposition of Neutral, Singly and Doubly Protonated Benzoquinone in the Gas Phase. Chem. Eur. J. 2005, 11, 628-638.

31. Schröder, D.; Schwarz, H. Thermochemistry of Neutral and Cationic Iron Hydroxides $\mathrm{Fe}(\mathrm{OH})_{n}{ }^{0 /+}(n=1,2)$ in the Gas Phase. Int. J. Mass Spectrom. 2003, 227, 121-134.

32. Gaussian 03, Revision C. 02. Gaussian, Inc.: Wallingford CT, 2004

33. Eland, J. H. D. Photoelectron Spectra of Conjugated Hydrocarbons and Heteromolecules. Int. J. Mass Spectrom. Ion Phys. 1969, 2, 471.

34. Evangelio, E.; Ruiz-Molina, D. Valence Tautomerism: New Challenges for Electroactive Ligands. Eur. J. Inorg. Chem. 2005, 21, 2957-2971.

35. Recent review: Sato, O.; Tao, J.; Zhang, Y.-Z. Control of Magnetic Properties through External Stimuli. Angew. Chem. Int. Ed. Engl. 2007, $46,2152-2187$. 